CAHIER DE RECHERCHE \#1301E

Département de science économique

Faculté des sciences sociales

Université d’Ottawa
WORKING PAPER \#1301E

Department of Economics

Faculty of Social Sciences

University of Ottawa

\title{
Dissent in Parliament as Reputation Building*
}

\author{
Brandon Schaufele $^{\dagger}$
}

August 2013

\footnotetext{
${ }^{*}$ Helpful comments on this version were provided by Randy Besco and Nicholas Rivers. All errors are my own.

${ }^{\dagger}$ Department of Economics and Institute of the Environment, University of Ottawa, 120 University, Ottawa, Ontario, Canada, K1N 6N5; Email: brandon.schaufele@uottawa.ca.
} 


\begin{abstract}
Dissenting votes in parliamentary systems are overt displays of defiance by individual Members of Parliament (MPs) vis-à-vis their parties. Dissension is particularly surprising as in the vast majority of situations voting against one's party yields no change in legislative outcomes while still generating costs for MPs. This study examines the decisions of elected representatives who face conflicting incentives. A model is developed where MPs choose to dissent in an effort to build reputations with their local constituents. Using all 32,216 observations at MP-bill-vote level for the 39th Parliament of Canada, a reputation building hypothesis is specified and tested. I provide evidence that MPs whose previous election was competitive are 13 percent more likely to cast any dissenting vote and, for a one standard deviation decrease in expected margin of victory, 2.3 percent more likely to defect on any given vote, results which suggest that MPs are actively attempting to build reputations with their local constituents.
\end{abstract}

Key words: Canadian Parliament; dissent; elections; local politics; politician behavior; reputation.

JEL Classification: D72, D78, H19.

\title{
Résumé
}

Les voix dissidentes dans les systèmes parlementaires sont une manifestation ouverte de défi par des députés vis-à-vis de leurs partis. La dissension est particulièrement surprenante, car dans la grande majorité des situations, ayant voté contre son parti ne donne pas de changement dans les résultats législatifs, mais génère des coûts pour les députés. Cette étude examine les décisions des élus qui font face à des incitations contradictoires. Un modèle est développé où les députés choisissent de différer afin de construire une réputation avec leurs électeurs locaux. En utilisant tous les 32216 observations au niveau député-projet de loi-vote pour la 39e législature du Canada, une hypothèse de construction de la réputation est spécifiée et testée. Je fournis la preuve que les députés dont l'élection précédente était compétitive sont 13 pour cent plus susceptibles de différer et, pour une diminution de l'écart d'une norme de la marge attendue de la victoire, de 2,3 pour cent plus susceptibles de faire défection à tout vote donné, des résultats qui suggèrent que les députés tentent activement de construire des réputations avec leurs électeurs locaux.

Mots clés: Parlement canadien, aucune contestation; élections; la politique locale; comportement politicien; réputation.

Classification JEL: D72, D78, H19. 


\section{Introduction}

Dissenting votes whereby individual Members of Parliament (MPs) vote against their party's position are uncommon in parliamentary systems, but they do occur. Parliamentary democracies are dominated by political parties, which hold tight control over legislative agendas. High degrees of party cohesion are observed as MPs face strong incentives to vote along party lines ${ }^{1}$ and due to the double monopoly of power (Palmer, 1995). ${ }^{2}$ Nonetheless, MPs do continue to dissent; indeed they do so in surprising circumstances that the extant literature has inadequately addressed - MPs frequently cast dissenting votes in situations where the outcome of a particular piece of legislation is a foregone conclusion. Governing parties, within parliamentary systems, seldom permit a bill to come to a vote unless there is a large probability of its passage and it is equally rare for opposition parties to obtain sufficient support to pass legislation. Given that dissenting votes are costly to individual MPs (as they lead to punishment) and that they have no observable effect on policy outcomes, it is a puzzle as to why MPs would deviate from their party's positions. Rational decision-makers would not incur a cost without some expected payoff. This paper theoretically and empirically examines legislative voting decisions of incumbent MPs vis-à-vis their parties. These situations provide an overlooked opportunity to examine a specific form of political exchange votes in legislature are exchanged for votes in a general election - in which MPs build reputations with their constituents and voters are made better off even though preferred policy outcomes are not realized.

Voters elect individuals who are members of political parties, who have private preferences and who must compete in local elections. Ultimately MPs are accountable to their constituents but no dominant theory encapsulates how local voters perceive the relationship between representatives and party, especially in light of the high observed levels of party cohesion. A model is constructed

\footnotetext{
${ }^{1}$ Parties punish dissenting MPs via several mechanisms (Bowler et al., 1999; Kam, 2009). Examples include demotion from cabinet, removal from prestigious committees, loss of influence with party leadership and possible expulsion from the party. Even the seating arrangement within legislatures confers an MP's status and level of influence. Political parties also control vital election parameters including the nomination process and a large share of campaign finance (Milligan and Rekkas, 2008); seldom can MPs get elected without support from a major political party. Most of these parameters are at the sole discretion of party leadership.

${ }^{2}$ Double monopoly of power refers to the stylized fact that within Westminster parliaments cabinet has (almost) complete control over the legislative agenda, while a single party has (almost) complete control of the cabinet's members. Together these institutional rules yield high degrees of party cohesiveness.
} 
where politicians weigh the consequences of dissent. When a politician casts a dissenting vote which does not influence a legislative outcome, she is attempting to build reputation in her local constituency with the expectation that she will be rewarded for her decision even though voters obtain nothing tangible in return from this choice. In equilibrium, MPs trade-off party punishments, local politics and private preferences when deciding how to vote on legislation. The benefits of dissent accruing to the MP must be greater than any punishments used to coerce members to vote according to party line. Voters' expected benefits improve as the MP's observable decision increases the probability that MP-voter preferences are similar. The theoretical model generates an empirical prediction (referred to as the reputation building hypothesis). This hypothesis is investigated using all recorded votes at the MP-bill-vote level for the 39th Parliament of Canada (32,216 observations). Examining the data at this level of detail permits important insights into the voting behavior of parliamentarians that has previously been neglected in the literature. In particular, having multiple votes on the same bill facilitates the use of legislation-specific fixed effects. By theoretically and empirically disentangling the incentives faced by MPs, I demonstrate that MPs are responsive to their constituents if (1) the most recent election was won by a narrow margin and (2) they are running for re-election. MPs whose previous election was competitive are 13 percent more likely to cast any dissenting vote and, for a one standard deviation decrease in expected margin of victory compared to the mean, 2.3 percent more likely to defect on any given vote, results which suggest that MPs are actively attempting to build reputations with their local constituents.

Legislatures are where major policy decisions are made, so identifying the incentives that individual MPs face is relevant for predicting the outcomes of contentious decisions (Carey, 2007). It is particularly interesting to examine political exchange in situations where decisions by individual MPs rarely alter outcomes - i.e., their decision to dissent is meaningless from a policy perspective - but where reputations matter. Specifically, this setting may yield insight into situations such as lobbying and political campaign contributions where actors engage in costly behavior without receiving direct benefits from these activities (Ansolabehere, de Figueiredo and Snyder Jr, 2003; Bronars and Lott Jr, 1997; Potters and Sloof, 1996; Stratmann, 2005). Individuals and corporations may reward political effort, not policy success, because the political actor may have a reputation for supporting specific issues. Moreover, MP dissent lends itself to examining familiar common agency 
problems (Dixit, Grossman and Helpman, 1997). Intuitively principles seek to reward agents for exerting effort, but face challenges determining the actual level of effort supplied when exogenous factors dictate outcomes. Dissenting votes within parliamentary systems afford a forum to investigate the implications of observable effort in a common agency setting. Finally, understanding which factors determine elected officials' voting behavior, in general, is a fundamental prerequisite for discussions of voting decisions, electoral reform or institutional design (Aghion, Alesina and Trebbi, 2004)..$^{3}$

Dissent and party influence has received some attention (Faas, 2003; Hix, 2002; Krehbiel, 2000; Wright and Schaffner, 2002). Kam (2009) outlines three individual-level hypotheses for MP dissent and party cohesion: preferences, institutional constraints and social norms. The preferences hypothesis emerges from Krehbiel $(1993,1999)$ and states that elected officials simply vote their preferences. Low observed dissension and high observed party cohesion are due to pre-election sorting. Candidates do not randomly sort into political parties; they choose organizations that best reflect their preferences. When MPs deviate from party positions, it is merely where their preferences differ. The institutional hypothesis places structure on the preference hypothesis. It claims that the formal rules and organizational structure of parliaments enable a subset of actors to control legislative agendas and pro-actively minimize dissent (Cox, 2000). MPs are thus constrained in the demonstration of their preferences as they do not have opportunity to fully express their interests. Finally, Kam describes a sociological perspective that posits that MP behavior is governed by social norms. These norms dictate rules of conduct for representatives, including strong disapproval of MPs who vote against their party. This study accepts that each perspective likely describes some variation in observed voting behavior but focuses on formalizing a precise reputation building mechanism within a narrower context. Concentrating on dissenting votes in conjunction with MP reputation facilitates two extensions to the prevailing hypotheses. First, by exploiting vote-specific decisions which do not influence legislative outcomes it is possible to establish equilibrium strategies for individual MPs. These strategies reflect the tradeoffs between personal preferences, party pressure and electoral margins within a multidimensional policy space emphasizing the influence of reputation for both MP and voter. Second, I undertake a detailed empirical study of these equi-

\footnotetext{
${ }^{3}$ Electoral rules and government form (e.g., presidential or parliament) also have important economic consequences (e.g., Voigt, 2011).
} 
librium strategies using data at both the MP- and vote-level. Using legislation-specific, vote-level data enables me to control for the roles of issue-specific preferences and local electoral prospects in an effort to identify the magnitude of the reputation building mechanism.

Concentrating on dissent within political parties improves the understanding of elected official behavior, but it also contributes to a broader discussion of cohesiveness within organizations, committees and other decision-making bodies. Political parties make decisions behind closed doors; yet when subordinates disagree with their leaders' decisions, the results are observable (at least in the case of votes). This provides an opportunity to examine organizational culture that is often unseen to outsiders. A burgeoning literature concentrates on the benefits and disincentives that lead individuals to adopt minority opinions. Recent examples include Meade and Stasavage (2008) and Harris, Levine and Spencer (2011). These papers investigate dissent on the United States' Federal Open Market Committee (FOMC) and the Bank of England's Monetary Policy Committee (MPC). Meade and Stasavage found that following the 1993 decision to release FOMC transcripts, both voting and non-voting Presidents of regional Federal Reserve Banks were less likely to express verbal dissent on policy decisions. They attribute the change in behavior to career concerns and the desire of FOMC members to establish a reputation for expertise. Alternatively, Harris, Levine and Spencer found that career background had little effect on an MPC members' decisions to dissent. They attribute the conflicting results to the "democratic deficit" that marks appointments to the MPC: whereas appointments to Federal Reserve Banks are highly political, the UK's appointment process is decidedly less politicized. Taking a different approach, Landier, Sraer and Thesmar (2009) examine the role of dissent in conjunction with the efficiency of decision-making within organizations, a scenario that is relevant for a party-based system.

This paper proceeds by first formally describing an MP's decision problem. Section 2 presents a reputation building model of strategic MP voting where both voters and party punishment are incorporated. For each legislative vote, an MP will dissent only if the benefits outweigh the costs, a result which enables the specification of the reputation building hypothesis. The description of the data, empirical methodology and results are in section 3. The empirical section tests on MPs' equilibrium strategies. Discussion and conclusions are in section 4. 


\section{Strategic Voting in Legislatures}

A canonical political agency model is used to generate a central empirical hypothesis. The salient feature of the model is that is yields equilibrium predictions of MP behavior on particular votes (i.e., it captures issue-specific decisions not weightings across all votes). Several assumptions are made in the model's development in order to better convey the underlying intuition of the reputation building mechanism. Many of these are not strictly necessary, but make the exposition clearer and generally correspond to the dataset under investigation. In particular, the model is stylized to focus on a parameter space where the stability of the parliamentary government is taken as given and dissenting votes are meaningless to policy outcomes. ${ }^{4}$ This corresponds directly to the empirical situation being studied. The model builds on Besley and Coate (2001, 2003) and List and Sturm (2006). Besley and Case (2003) and Besley (2007) provide general overviews of political agency models.

\subsection{Political Environment}

An MP must vote on both an economic and social policy. The politician's party instructs the MP how she must vote on both. The politician, who joined the party because she agreed with its economic policy, must decide whether to vote with her party or dissent on the social policy. ${ }^{5}$ If she dissents, her party imposes a penalty. ${ }^{6}$ The MP receives an ego-rent from holding office in the current and future periods as well as utility from voting according to her private policy preferences. The equilibrium is a reputation building equilibrium where the MP's parliamentary voting record on social policy influences the probability that a fraction of her community will re-elect her.

A community with $N$ voters must make two policy decisions. There are an infinite number of periods. Voters have infinite lives and their preferences are heterogeneous across both policy

\footnotetext{
${ }^{4}$ See Diermeier and Feddersen (1998) for a model how party cohesion emerges in parliamentary democracies.

${ }^{5}$ This characterization closely matches the empirical situation analyzed. The vast majority of dissenting votes are on bills which would be classified as social issues. Very few dissenting votes were cast on legislation which would be labeled as primarily economic.

${ }^{6}$ Treating parties' legislative positions as exogenous is plausible. Party decisions are driven by party leadership and backbench MPs often feel as though they have little influence over party policies (Carey, 2007; Garner and Letki, 2005).
} 
dimensions. The first policy decision, an economic policy choice, involves selecting the overall level of public spending, $g$. Public spending is financed via a uniform tax on all citizens. Second, the social policy decision involves a binary choice $s \in\{0,1\}$ (whether or not to support gay marriage, for example), where $s=1$ indicates that the social policy was adopted and $s=0$ implies it was rejected. The social policy has a negligible budgetary impact.

Assume that there are four types of voters, $k \in\{L, R, P, A\}$. The share of each type of voter in the community is denoted by $\gamma_{k}$. Types $L$ and $R$, colloquially left- and right-wing voters, are party loyalists and derive utility solely from the level of public spending. Assume $g^{*}(L)>g^{*}(R)$. $L$ and $R$ voters are indifferent with respect to the social policy. $P$ voters are pro-social policy. They receive a payoff equal to $x>0$ if $s=1$ and zero otherwise. $A$ are anti-social policy and receive $x>0$ if $s=0$ and zero otherwise. For both $P$ and $A$ voters, preferences over $s$ dominate preferences over $g$ - i.e., they are "single issue voters" whose exclusive focus is social not economic policy (List and Sturm, 2006).

Policy-making is delegated to an elected official. These officials are MPs who belong to a political party. Candidates are drawn from two parties, a right- and left-wing party. Candidates choose their party based upon economic policy only. The political party of each candidate is known and does not change. Preferences over the social policy dimension are private. Voters believe that a randomly selected candidate is in favour of the social policy with probability $\pi$. This probability is updated as MPs build reputations for supporting or opposing the social policy.

The payoff function for MP $i$ with respect to her vote on the social policy takes the form:

$$
v_{i}\left(\delta_{0}\right)+\lambda_{i}-c_{i}\left(\delta_{1} ; \varepsilon_{i}\right)
$$

where $\delta_{0}=\left|s_{0}-s_{i}\right|$ and $\delta_{1}=\left|s_{p}-s_{i}\right|$. There are three components to (1). The politician's private policy preference is denoted by $s_{0}$ and, as above, $s_{i} \in\{0,1\}$ is an indicator variable signifying how the individual actually votes (a value of one implies a vote for the social policy). The MP's preferences for the social policy dimension are captured by $v_{i}(\cdot)$, with $v_{i}(0)>0$ and $v_{i}(1)<0$. This is legislation-specific and varies on a vote-by-vote basis. For example, assume that the MP's 
private preference is pro-social policy. If she votes for that position (i.e., $s_{i}=1$ ), then she receives a positive utility value (i.e., $v_{i}(0)>0$ ). Alternatively, if the MP strategically votes against her preferred policy, then she incurs a disutility cost (i.e., $\left.v_{i}(1)<0\right)$. Next, the "ego-rent" that the MP derives from holding office is given by $\lambda_{i}{ }^{7}$. The third element of (1) is the penalty. When MPs cast dissenting votes, parties impose penalties on those individuals. The term $c_{i}\left(\delta_{1} ; \varepsilon_{i}\right)-$ with $s_{p}$ representing the party's stated position, $c_{i}(1)>0$ and $c_{i}(0)=0$ - is the cost to the politician for opting to dissent. For example, if both the MP and the party are pro-social policy then $s_{p}=1$, $s_{i}=1$ and $c_{i}(0)=0$. The timing of the model adds uncertainty to the party's potential penalty. At the instant of the vote, the MP only knows the expected penalty. Uncertainty is captured by $\varepsilon_{i}$ that has bounded support $\left[\bar{\varepsilon}_{i}, \tilde{\varepsilon}_{i}\right]$. Finally, two restrictions are imposed on (1). First, E $c_{i}(1) \geq v_{i}(0)$. Absent of election incentives, this means that the party's expected punishment is greater than an MP's private preferences. ${ }^{8}$ The second restriction is $c_{i}(1)-v_{i}(1)>\lambda_{i}$. This states that the benefits from holding office are less the combined costs of the party's punishment and disutility from voting against one's private preference are less the payoff from holding office. This condition prevents an MP from dissenting when her private preferences are actually aligned with her party's. ${ }^{9}$ These restrictions are broadly plausible and enable the model to generate well-defined empirical predictions.

Due to factors such as spoiled ballots, missing ballot boxes and shocks to voter turnout, the outcome of an election contains randomness. Let $\omega$ denote the lead of party $R$ if there were no shocks to the election outcome - i.e., $\omega$ equals the total share of voters that support $R$ that is greater than one half. There is a shock that distributes some $R$ votes to $L$. Denote this shock by $u$ and assume it has a symmetric density $h(u)$ that is single-peaked and unbiased. The cumulative distribution function for $h(u)$ is $H(u)$. The probability the $R$ candidate wins is increasing in $\omega$ and equals $1-H(\omega)$ (i.e., without a shock $\mathrm{R}$ wins with probability 1 ).

\footnotetext{
${ }^{7}$ This is the present value of the current and future ego-rents, so captures re-election incentives.

${ }^{8}$ This is tantamount to saying that economic preferences dominate social preferences. Another way of stating this is politicians select which party to become a member using a lexicographic decision process, likely an accurate reflection of actual decisions.

${ }^{9}$ This condition is partially implied by the sorting process where MPs select which party to join. In practice however, it may be too restrictive. For example, if an individual only receives utility from holding office and is privately indifferent with respect to policy outcomes, then this condition collapses to a comparison of punishment versus ego-rent.
} 


\subsection{Timing and Equilibrium}

The model assumes that politicians do not face term limits per se. Instead, assume that following two terms MPs receive a non-political offer whose value exceeds the sum of ego-rent and policy utility. The outside option for the first and second term MPs is normalized to zero.

There are three stages in the model. In stage one, an MP votes on both $g$ and $s$. These votes are observed by voters as well as the MP's party and they serve to build the MP's reputation. Dissenting MPs know the expected value of $c_{i}$ at the time of the vote. Once voting on economic and social policy is complete an election is held. Elections, the second stage of the model, allow voters to hold incumbent MPs accountable for their policy choices. If the incumbent MP has not received an outside offer (i.e., has only served one term), she faces a randomly selected challenger. In the event that the incumbent does not run, both parties randomly select candidates. In the third stage, if (i) an incumbent is reelected and (ii) she dissented from her party's stated position in stage one, a realization of $c_{i}$ is imposed on the politician by her party.

A Markov perfect equilibrium can be defined for the game between MPs and voters. In particular, the equilibrium is defined by a set of strategies that maximizes the value functions for MPs and voters given the strategies of the other players. Each player's optimal strategy involves a rule which includes the probability that they undertake a particular action. An MP's strategy is a rule that determines the probability that they vote for the social policy. This strategy is a function of the terms in her payoff function (i.e., (1)) and the electoral margin (e.g., number of pro-social policy voters relative to anti-social policy voters): $\gamma_{P}-\gamma_{A}$. A dissenting vote, then, is defined as a situation where the individual MP selects an optimal strategy that leads her to vote against the position of her party.

The optimal strategy for party loyalists, voters who only care about the economic policy (i.e., $k=L$ and $k=R$ ), is a rule that states the probability with which they, respectively, vote for the left- and right-wing candidate. Finally, the strategies of pro- and anti-social policy voters are comprised of two parts. The first part is a rule that specifies the probability that each votes for the $R$ candidate if two challengers are running in an election. This is simply $\pi$ as stipulated. The 
second part specifies the probability that he supports the incumbent after observing her vote on the social policy. This probability is derived via an updating procedure (Bayes rule). It is through this updating procedure that MP reputation induces voter decisions.

Politicians do not dissent with respect to economic policy. So, the optimal strategy for left- and right-wing voters is to always vote for the corresponding left-wing and right-wing candidates. As a result, the model only needs to be solved for the strategies with respect to the social policy.

To start, apply backward induction to determine the MP's optimal strategy. By assumption, the second term is the MP's last in office. Therefore, neither the party's punishment not the risk of not being re-elected factor into the politician's payoff function. As such, she will vote according to her private policy preference. The politician's strategy during her first term needs to account for the both electoral incentives and the position of her party. There are four potential strategies. First, consider the situation where both the MP and her party support the social policy. In this case, as $\gamma_{P}>\gamma_{A}$, the MP does not dissent and chooses $s_{i}=1$. Now consider the case where both the party and the MP are anti-social policy. It was assumed that $c_{i}(1)-v_{i}(1)>\lambda_{i}$. In this circumstance as well, the MP's optimal strategy is do not dissent. Next, consider a right-wing politician who is prosocial policy, while her party's position is anti-social policy. If this MP dissents and votes in favour of the social policy, her probability of re-election will increase from $1-H\left[-\left(\gamma_{R}-\gamma_{L}\right)+\left(\gamma_{P}-\gamma_{A}\right)\right]$ to $1-H\left[-\left(\gamma_{R}-\gamma_{L}\right)-\left(\gamma_{P}-\gamma_{A}\right)\right]$. This can be written: $\int_{-\left(\gamma_{R}-\gamma_{L}\right)+\left(\gamma_{P}-\gamma_{A}\right)}^{-\left(\gamma_{R}-\gamma_{L}\right)} \Gamma\left(\gamma_{P}-\gamma_{A}\right)$. Therefore, in order for the MP to dissent, it must be the case that:

$$
v_{i}(0)+\Gamma\left(\gamma_{P}-\gamma_{A}\right) \lambda_{i}>\mathbf{E} c_{i}(1)
$$

Thus an MP's decision to dissent is comprised of three components (due to the symmetry of the model, other dissenting strategies (e.g., party L who is pro-social party with an MP that is anti-social policy) mimic the expression in (2)). First, there is the bill-specific private preference, $v_{i}(0)$. This factor is unobservable, yet in repeated votes the average legislation-specific subject matter effect of a particular bill can be accommodated with fixed effects. (Necessary identifying assumptions are discussed in section 3.) The second component in (2) is the product of electoral margins and re-election incentives (ego-rent): $\Gamma\left(\gamma_{P}-\gamma_{A}\right) \lambda_{i}$. For the case of a right-wing politician, 
the likelihood of dissent is increasing in $\gamma_{P}-\gamma_{A}$ and decreasing in $\gamma_{R}-\gamma_{L}$ - that is, as the fraction of non-party loyalists increases, the likelihood of an MP casting a dissenting vote increases. This means that conditional on party fixed effects (which capture the shares of party loyalists) the safer the seat as measured by expected electoral margin, the less likely it is that the MP will dissent. Another way to state this is: if there is no value to building a reputation, the MP will not incur the punishment associated with casting a dissenting vote. Finally, the expected party punishment, $\mathbf{E} c_{i}(1)$, is also unobserved, but is treated as a latent threshold whereby observed dissension implies that the left-hand side terms in (2) outweigh the party's punishment.

Intuitively, MPs make observable decisions and these decision influence how voters perceive of their representatives. A colloquial example of political reputation can be seen via common political labels such as "fiscally conservative but socially liberal". These labels are a manifestation of MP behavior because political observers see how politicians vote. While voting is not the only mechanism that establishes reputations, it is a clear signal to voters. Moreover, this set-up enables me to define a latent variable model with two conditions which capture the interplay of reelection incentives and electoral margins. Precise formulation of the empirical reputation building hypothesis is described in the next section

\section{Empirical Hypotheses and Results}

Testing reputation building proceeds in several steps. ${ }^{10}$ First, the data are reviewed and then the main reputation building hypothesis is specified. Before directly testing this hypothesis however, two preliminary hypotheses are examined. Throughout, multiple empirical methods such as matching, count models and sample selection approaches are employed in an effort to establish the appropriate counterfactual and tease out whether it really is local politics that is driving at least some portion of MPs voting behavior. Overall, coefficient estimates provide strong suggestive support for the idea that MPs use dissenting votes to build reputations with their constituents. Results at the MP-level are compelling and statistically significant. Point estimates for the basic vote-level models support reputation building across all specifications, but only when I accommodate selection

\footnotetext{
${ }^{10}$ Data and code for all empirical models will be posted on the author's website.
} 
on unobservables am I able to reject the null of no reputation building.

\subsection{Data}

To examine the roles of electoral incentives and reputation on legislative votes, I merge data from two sources. First, all 32,216 votes cast by every MP in the 39th Parliament of Canada were retreived from LEGISinfo. ${ }^{11}$ LEGISinfo, a collaborative service of the Senate, House of Commons and the Library of Parliament, is the official database that provides a record of all proposed, current and enacted legislation within the Parliament of Canada. Next, information on candidate lists, electoral margins and several control variables such as voter turnout was retrieved from Elections Canada.

Table 1 displays descriptive statistics for this dataset. The 39th Parliament was a minority government led by the Conservative Party of Canada. Comprised of two sessions, it ran from April 3, 2006 to September 7, 2008. At the onset, there were 308 MPs from four parties - the governing Conservative Party of Canada had 124 MPs, the Liberal Party of Canada had 103 MPs, New Democrat Party had 29 MPs and the Bloc Québécois had 51 MPs. ${ }^{12}$ Votes were cast on 65 pieces of legislation. On 35 bills unanimity prevailed and no dissenting votes were cast. There were 30 pieces of legislation where at least one MP deviated from her party's stated position. ${ }^{13}$ In the end, 13,734 votes were cast on legislation that was "contentious" ${ }^{4}$ with a total of 445 dissenting votes reflecting 1.1 percent of all votes cast and 3.2 percent of votes cast on legislation where at least one MP dissented. Notice that the standard deviation on these means are large, equaling 10.4 and 17.9 percent, respectively. This hints that, even though most bills had no dissent, there was conspicuous

\footnotetext{
${ }^{11}$ These votes were retrieved using Perl code adapted from howdtheyvote.ca (http://howdtheyvote.svn.sourceforge.net/viewvc/howdtheyvote/branches/geog/scripts/). This code will be bundled with the other data and code used in the analysis. LEGISinfo has reformatted their database (more than once) since this code was originally adapted, so some edits would be required to replicate the dataset.

${ }^{12}$ These counts reflect party membership at the start of the 39th Parliament. Throughout the session, there was one death and 12 resignations and of these vacancies nine seats were filled with by-elections. Five MPs also crossed the floor during this Parliament - three moved to the Conservative party and two to the Liberal party.

${ }^{13}$ Dissent in the Canadian Parliament is much less common than in many other jurisdictions such as the British Parliament (Kam, 2001). Longley (1998) states "in the Canadian Parliament, party discipline is so strong that individual MPs are almost always forced to vote in accordance with the position adopted by their party" (121).

${ }^{14} \mathrm{~A}$ selection of issues receiving dissenting votes includes: whether Canada should have extended its participation in the Afghan War, reaffirmation of the Kyoto Protocol, a bill that would introduce fixed election dates, several crime bills, the continuation of anti-terror laws and whether Canada should re-open the same-sex marriage debate.
} 
dissent on controversial bills. Throughout, most analysis is conducted on the full sample; however, select robustness checks restrict the sample to bills that had some dissent. This choice reflects a trade off. Often votes in the Canadian House of Commons are procedural and no defection is expected. Analysis on a restricted sample then yields a less noisy test of reputation building as MPs are unlikely to send signals to local constituents over procedural votes. Focusing on bills where some dissent occurs however may generate bias due to selection on the dependent variable, so caution must be exercised when interpreting these models. With the information available, it is not possible to determine whether a vote was actually procedural or was a contentious vote that bore no dissent.

As Table 1 illustrates, only 188 out of 308 MPs (61.0 percent) dissented, with Members of the Liberal Party being the most likely (86.4 percent) and Bloc Members being least likely (27.4 percent) to deviate from party policy. The average margin of victory for all MPs and MPs who dissented was 21.9 and 20.0 percent, respectively, with corresponding standard deviations of 15.4 and 15.3 percent. Other covariates considered in the empirical models include cabinet membership, home province an bill-specific indicators (fixed effects).

The main empirical hypothesis depends on two variables: a re-election indicator and the margin of victory. Both are retrieved from Elections Canada. The re-election variable is subject to potential self-selection. Conditional on their expected margins of victory, if MPs make strategic choices with respect to their re-election prospects, the co-efficient on the re-election dummy will be upwardly biased. I follow Hainmueller and Kern (2008) and Kendall and Rekkas (2012) by assuming no strategic exit. This is a potentially strong assumption which implies that individuals whose probability of re-election is low do not strategically select an outside option. Yet, high propensities to run for re-election in Canadian federal politics gives some reassurance that this assumption is not unduly restrictive. Next, the margin of victory variable, an MP's expectation of her margin in the next election, is proxied by the previous election's margin of victory. MPs in the 39th Parliament of Canada attempt to build reputations to increase their margins of victory in the 40th General Election of Canada. The vast majority of MPs do not perform riding-level polls; as a consequence, conditional on party fixed effects, an MP's best prediction of her future electoral prospectives is 
assumed to be her previous margin of victory. ${ }^{15}$ In other words, the previous election's margin of victory is the most recent quantitative information available and thus yields the best indicator of future electoral margins. Each MP's electoral margin in the 39th election is used to represent the individual's expected margin. In the results section, this assumption is relaxed in a robustness check using a subset of the data and an instrumental variable strategy whereby MP's margin of victory in the 40th General Election (for the subset of MPs who ran for re-election) is used as the expected margin variable; this variable then is instrumented with the margin from the previous election. Neither the strategic exit nor the expected margin of victory assumptions are viewed as implausibly burdensome; still it is worth noting the potential sources of bias.

\subsection{Main Hypothesis}

The core theoretical prediction in this study is referred to as the reputation building hypothesis. Eq.(2) permits the specification of a of latent variable model, yielding grounds to test MP motivations and whether reputation building is a viable explanation for MP dissent. For the analysis that uses vote-level data, it is possible to write:

$$
V_{i j k}=\mathbf{1}\left\{\phi_{j}+\beta_{1} \operatorname{Margin}_{i}+\beta_{2} \text { Reelection }_{i}+\beta_{3} \operatorname{Margin}_{i} * \text { Reelection }_{i}+u_{i j k}>0\right\} .
$$

$V_{i j k}$ is the dependent variable that takes the value of 1 if $\mathrm{MP} i$ dissents on bill $j$ during reading $k$. $\phi_{j}$ represents legislation-specific fixed effects, parameters which capture the contribution of the given bill to the probability that a dissenting vote is recorded. ${ }^{16} \operatorname{Margin}_{i}$ is MP $i$ 's expectation of her next election's margin of victory. This reflects the solved integral represented by $\Gamma\left(\gamma_{P}-\gamma_{A}\right)$ in (2). Reelection ${ }_{i}$ is a binary variable that indicates whether the MP runs for re-election in the subsequent election. The interaction term, $\operatorname{Margin}_{i} *$ Reelection $_{i}$, captures the combined effect of expected electoral margin and re-election incentives. Finally, $u_{i j t}$ is a composite error term

\footnotetext{
${ }^{15}$ The theoretical model invokes a Markov property which, mimicking this assumption, implies that all relevant information is embodied in the most recent realization of an observation.

${ }^{16}$ These bill-specific fixed effects are only identified for bills that have variation in the voting patterns - i.e., votes that had at least two dissenting votes cast.
} 
comprised of fixed effects and control variables and, in general, can be decomposed as:

$$
u_{i j t}=\zeta_{i}+\mathbf{X} \beta+\nu_{i j t}
$$

where $\zeta_{i}$ are party fixed effects, $\mathbf{X} \beta$ controls for other relevant variables such as cabinet membership and MP home province and $\nu_{i j t}$ is a vote-specific error term.

No clear prediction can be made on the signs of the margin and re-election coefficients $\left(\beta_{1}\right.$ and $\beta_{2}$, resp.). If an MP opts not to run for re-election, reputation with local constituents is less important and, as incentives are unclear, it is not possible to make predictions about the sign of electoral margin on the probability of dissent: $\beta_{1}$ could be greater or less than zero. It is also not possible to unambiguously sign $\beta_{2}$. While the explicit influence of electoral margins and reelection dummies on the probability of casting a dissenting vote must be determined empirically, the theoretical model does predict that the expected coefficient on the margin-re-election interaction should be negative $\left(\beta_{3}<0\right)$. As the expected margin of victory increases, an MP's seat becomes safer and she has no need to engage in costly reputation building with local voters. So for every percentage point increase in the expected margin of victory, the reputation building theory suggests that there should be a decrease in the likelihood that an MP will dissent. This is because the benefits to dissent shrink as the local seat becomes more secure for a given penalty. Yet, examining the coefficient on the interaction term is insufficient to conclude that reputation building is a factor in MP dissent. Because the coefficient of re-election is ambiguous, the specification of joint hypothesis is required. Specifically, my main empirical hypothesis is:

Reputation Building Hypothesis - The reputation building hypothesis states that MPs cast dissenting votes in an effort to build reputations with their local constituents and bolster their chances in the next general election. This hypothesis requires that two conditions are satisfied: (1) the coefficient on the re-election-margin interaction should be negative and (2) the sum of the re-election indicator and the negative of the reelection-margin coefficient should be greater than zero. Formulating these as rejectable nulls:

1. $H_{0}^{\mathrm{I}}: \beta_{3}>0$ versus an alternative of $H_{A}: \beta_{3} \leq 0$, and 
2. $H_{0}^{\mathrm{II}}: \beta_{2}-\beta_{3} \leq 0$ versus an alternative of $H_{A}: \beta_{2}-\beta_{3}>0$.

The empirical analysis presented in the subsequent sections focuses on testing various formulations of this hypothesis. The reputation building hypothesis emphasizes that MPs will alter their behavior in an attempt to influence voters. Attention is paid to MPs' voting conduct; no claims are made about nor does any model analyze the success of this strategy. Further, while selection on observables is clear - parties may impose differential penalties and demotion from cabinet, for instance, is more costly than, say, reassigned seating - there may also be selection on unobservables

- some MPs may have an innate inclination towards dissent. Controls are included for the key observables (e.g., party) and selection on observables is plausibly the dominant form of potential bias. Nonetheless, key models and robustness checks test for selection on unobservables and section 3.6 demonstrates that unobserved heterogeneity is an important influence on MP behavior.

\subsection{Are MPs in Competitive Ridings More Likely to Dissent?}

Prior to investigating results on counts or at a the vote-level, I investigate whether MPs whose previous electoral victory was competitive are more likely to dissent. The underlying intuition of reputation building is that MPs cast dissenting votes in response to narrow margins of victory. As dissent has a cost and if it is unlikely that they will be unseated in a subsequent election (because their margin of victory was large), it is equally unlikely that they will incur their party's punishment in an effort to build reputation. An initial test of this intuition involves examining whether MPs whose margins of victory were small are more likely to cast dissenting votes than those whose margins of victory were large.

In order to test this basic hypothesis, a conventional matching procedure is employed (e.g., Ho et al. (2007)). Two dichotomous variables are defined. The first takes a value of one if the MP won her seat by a margin of victory of less than or equal to 10\%. The second takes a value of one if the MP won her seat by a margin of victory of less than or equal to 5\%. A matched sample of MPs is then generated where some MPs are "treated" by being assigned to a competitive riding while other 
MPs who share the same characteristics with the exception of being in a tight race act as controls. ${ }^{17}$ Assignment was operationalized using propensity score methods where weights are computed using a kernel approach (Smith and Todd, 2005). A Gaussian kernel is applied entailing the use of all control group observations. Estimation of the probability models employs variables that were determined prior to individual voting, so are very unlikely related to MPs' eventual decisions to dissent. These include province of origin, party membership and whether the MP was a member of cabinet. ${ }^{18,19}$ All MPs were on the common support for the 10 percent threshold, while 70 were dropped for the 5 percent cut-off; t-tests of the covariates for treated and control samples show no statistically significant differences between the groups; and, finally, before the average treatment values were calculated, the sample was trimmed by 2 percent to avoid potentially unreliable regions of the distribution (Frölich, 2004).

Table 2 demonstrates that MPs in competitive ridings are more likely to dissent. The value of interest is the average treatment effect on the treated. This reflects the difference in the probability that an MP who won her previous election by less than 10 or 5 percent, respectively, casts a dissenting vote minus the probability that a MP who won by more than these margins dissented. An MP whose previous electoral victory was by a margin of less than 10 percent is 12.7 percent more likely to dissent than an MP whose victory was by more than this margin. This difference is statistically different from zero at a 5 percent level. Using a more restrictive definition of competitive election, the likelihood that an MP will dissent increases by 6 percent. A margin of victory of 5 percent of less implies that an MP who may be trying to build a reputation is 18.6 percent more likely to cast a dissenting vote than one who is not. This estimate is also statistically significantly different from zero.

Table 2 provides compelling evidence that conditions in local districts influence MP voting behavior. MPs whose next election fight is expected to be tight, based on their previous margin of victory, are more likely to cast a dissenting vote compared with matched MPs whose seats are relatively safe. This suggests that MPs are attempting to build reputations in their local constituencies

\footnotetext{
${ }^{17}$ There are 76 ridings classified as close according to the 10 percent threshold and 38 according the to 5 percent threshold.

${ }^{18}$ Several MPs were appointed to cabinet mid-session. Cabinet appointment is still included in the matching models, but the results are robust to its exclusion.

${ }^{19}$ Parameter estimates from the probability models are available upon request.
} 
via their voting behavior as the matching procedure compares two groups of politicians whose only observable difference (in probability) is their expected margin of victory. In other words, if two MPs who were otherwise identical were interchanged, the conditions in the local constituency would motivate distinct behavior conditional on party punishments.

While these estimates are persuasive, there are two caveats. First, this is not a direct test of the reputation building hypothesis. The theory stipulates that it is the interaction of re-election incentives and margin of victory at the vote-level that links dissent to reputation. ${ }^{20}$ Second, matching methods require the assumption of unconfoundness or strong ignorability. This implies that the only difference between the two samples is that one group was in a tight local election and the other was not. Insofar as there are omitted factors or unobserved heterogeneity determining whether a given MP was in a close election the average treatment effect on the treated will be imperfectly estimated. Conditional on party membership, home province and cabinet membership, it is believed that unconfoundedness is broadly plausible.

\subsection{Count Data Models}

The next step in the analysis builds on the coarse dissent dummies and examines aggregated dissenting vote counts. Table 3 presents estimated coefficients from a negative binomial model on the number of times an MP cast a dissenting vote. ${ }^{21}$ Three columns of results are presented. The first column displays the estimated coefficients from the count model. The coefficient of the re-election indicator equals 0.58 and is statistically significant at a 10 percent level. The point estimate on the interaction term is a statistically significant (at a 10 percent level) -0.02. As this coefficient is negative, the first condition of the reputation building hypothesis is satisfied. The Chi-squared statistic in the bottom row of the table is a test of the second condition - the joint hypothesis. It is possible to reject the null of no reputation building at a 10 percent level indicating that MPs do appear responsive to their local constituents.

\footnotetext{
${ }^{20} \mathrm{~A}$ matching exercise similar to the one in Table 2 was completed using a re-election indicator rather than a competitive riding indicator. MP's who dissented were 4 percent less likely to run for re-election compared with those who did not dissent. The bootstrapped 95 percent confidence on this estimate included zero and equaled $(-11.1 \%, 2.6 \%)$. As discussed, it is not possible to sign the uninteracted re-election variable.

${ }^{21} \mathrm{~A}$ test of over-dispersion found that a negative binomial formulation is preferred to the Poisson.
} 
The second and third columns in Table 3 calculate the marginal effects at 10 and 5 percent margins of victory, respectively (corresponding with the cut-offs in Table 2). Comparing an MP at the mean margin of victory ( 21.9 percent) to one at the 10 percent threshold reveals that the individual in the competitive riding will cast 0.73 more dissenting votes. ${ }^{22}$ Making the same comparison for the threshold at 5 percent (so slightly more than one standard deviation below the mean) shows that these MPs will cast 0.86 more dissenting votes. Combining these results with Table 2 demonstrates that MPs who won closely contested elections are more likely to defect and, as their margins of victory shrink, they will cast more dissenting votes than the average MP.

Results at the MP-level offer convincing evidence that MPs do cast more dissenting votes in response to local electoral conditions and underpin the reputation building description of politician behavior proffered above. The next two subsections move to vote-level data to control for billspecific factors that may drive dissent.

\subsection{Marginal Probability of Dissent with Vote-level Data}

The reputation building hypothesis is formulated on a vote-level. Factors such as the party culture or the subject matter of a bill may explain much observed dissension; only by examining the data on a vote-by-vote basis is it possible to control for legislation-specific influences and parse preferences from reputation. Legislation-specific and party fixed effects as well as several additional control variables are included in all models presented in Tables 4 through 6 . Party fixed effects capture vote invariant characteristics such as ideology and longstanding culture. Some parties, for instance, may impose larger punishments on dissenting MPs. Legislation-specific fixed effects accommodate variation in voting patterns that is attributable to level of controversy or subject matter of specific bills. There were high levels of dissent, for example, on legislation which extended Canada's role in the Afghanistan War. Controlling for factors which are explicitly tied to an issue yields a sharper picture of the role of reputation. Bill-specific controls also mitigate residual concerns that it is MP preferences driving voting decisions rather than local politics.

\footnotetext{
${ }^{22}$ This is calculated as re-election + interaction*relevant margin $(0.49+0.02 *(21.9-10.0))$.
} 
Table 4 presents the basic tests of the reputation hypothesis using the full sample of vote-level data. Point estimates support the theory but are not statistically distinguishable from zero. Table 5 presents robustness checks on these results. Finally, Table 6 considers selection on unobservables and ultimately finds persuasive support for reputation building at the vote-level after accommodating unobserved heterogeneity.

Table 4 estimates the basic vote-level model using least squares and probit. ${ }^{23}$ Two conditions are needed for reputation building. First, the interaction term between re-election and margin of victory must be negative. This is evident in both specifications, although neither is statistically distinguishable from zero. For the least squares model, the interaction term equals -0.02 , while for the probit model it is -0.05 . Combining this with the re-election indicator implies that a one standard deviation (15.4 percent) decrease in expected margin of victory will lead to a 0.9 (least squares) and 1.8 (probit) percent increase in the probability that an MP running for re-election will dissent on any given vote. Yet, while the coefficients have the appropriate sign and have non-trivial magnitude, the F-stats at the bottom of the table indicate that it is not possible to reject the null hypothesis of no reputation building. While politically meaningful on the vote-level, attempts to build reputation are not significantly different from zero.

\section{Robustness Checks}

Table 5 presents three alternative specifications. Results confirm those in Table 4. Coefficients consistently have the predicted sign and magnitudes are similar across specifications. Statistical significance is elusive as it is not possible to reject the null of no reputation building.

As discussed, often votes in the House of Commons are procedural with no dissent is expected. (1) presents a linear probability model for a restricted sample of bills that had at least one dissenting vote. This reduces the number of observations to 13,734. The estimated marginal effects

\footnotetext{
${ }^{23}$ The preferred models are estimated as linear probability models. Two arguments support a linear probability model over the probit (Angrist and Pischke, 2008). First, the reputation building hypothesis refers to marginal effects not structural parameters and the linear probability model is a good approximation the unknown conditional expectation function. Second, much of the identification is driven by a large number of fixed effects and the linear probability has reasonable properties when many parameters are estimated. Marginal effects are very similar between the two methods.
} 
corresponding to electoral margin, re-election and their interaction are 0.04 percent, 1.60 percent and -0.06 percent. The magnitude of the margin effects is larger than Table 4, but still not significantly different from zero. The joint hypothesis indicates that an MP running for re-election is 2.5 percent more likely to dissent on any given parliamentary vote for a one standard deviation decrease in mean margin of victory. The F-stat is 1.05 (p-value 0.3).

Next, the model in (2) applies an inverse propensity score weighting approach. This is methodology, discussed in Rosenbaum and Rubin (1984) and Glynn and Quinn (2010), blends matching and regression. The full sample is used and the estimated marginal effects have the appropriate signs, but the coefficients are not statistically distinguishable from zero. The marginal effect of reputation building (joint hypothesis) equals 1.2 percent. ${ }^{24}$

Finally, (3) in Table 5 tests another key assumption underlying Table 4 - conditional on party fixed effects, MPs' best prediction of their next margin of victory is assumed to be their previous margin of victory. This research focuses on local ridings. In Canada, most (if not all) MPs do not seek midterm quantitative estimates of their future electoral prospects; rather, support is gaged qualitatively (e.g., via personal conversations, letters in local newspapers, etc.). As the expected margin of victory is central to the reputation building hypothesis, (3) uses the margin of victory in the 40th election as the relevant variable. Clearly this margin is endogenous to the MP voting patterns displayed in 39th Parliament of Canada and biased estimates will be generated. Thus an instrumental variable model is specified where the margin in the 39th General Election is used to instrument for the margin in the 40th General Election. This strategy limits the sample to MPs who ran for re-election and implies that reputation effects are fully captured by the electoral margin variable rather than the joint hypothesis. The coefficient in (3) has the predicted sign but is smaller in magnitude, equaling -0.01 , and is not statistically significantly different from zero. ${ }^{25}$

Evidence presented in Tables 4 and 5 indicates that voting patterns are consistent with the

\footnotetext{
${ }^{24}$ These estimates in Table 5 are the most conservative of several inverse propensity score weighting models. Alternatives which included using the the propensity score as variable in the main regression (control function approach) are also run giving larger marginal effects, similar to the linear probability model.

${ }^{25}$ The negative sign on this coefficient is reassuring even though it is not statistically significant at conventional levels. Instrumental variable estimates have inflated standard errors and, conditional on other models' lack of significance, lack of significance is unsurprising.
} 
reputation building hypothesis, but it is not possible to reject the null of no reputation building. Personality or other factors such as local media attention however may make it more likely that a subset of MPs will cast dissenting votes. Selection on unobservables, in other words, may mask some of the reputation building effect. I investigate this next.

\subsection{Vote-level Data with Potential Unobservable Heterogeneity}

Nearly 40 percent of MPs did not cast a dissenting vote in the 39th Parliament of Canada. Key factors such as party and whether or not the individual is a member of cabinet explain why some MPs may face differential costs and benefits from defection. Yet innate or unobserved qualities may also lead some individuals to dissent; indeed, these characteristics may mask the reputation building effect. To this end, I use a Heckman-style Type II Tobit approach which separates the decision to dissent from the propensity to dissent on any given vote. As these unmeasured MP characteristics may affect both of these decisions, a specification is required that permits correlation between observables and error terms. Specifically, consider the model:

$$
\begin{gathered}
D_{i}=\mathbf{1}\left\{\alpha_{1} \operatorname{Margin}_{i}+\alpha_{2} \text { Reelection }_{i}+\alpha_{3} \operatorname{Margin}_{i} * \operatorname{Reelection}_{i}+u_{i}^{1}>0\right\} \\
V_{i j k}=\mathbf{1}\left\{\phi_{j}+\beta_{1} \operatorname{Margin}_{j}+\beta_{2} \text { Reelection }_{j}+\beta_{3} \operatorname{Margin}_{j} * \text { Reelection }_{j}+u_{i j k}^{2}>0\right\} \\
\text { with } \\
u_{i}^{1}=\xi_{i}+\mathbf{X} \alpha+v_{i}^{1} \\
u_{i j t}^{2}=\zeta_{i}+\mathbf{X} \beta+v_{i j t}^{2} \\
\text { and } \\
{\left[\begin{array}{c}
v_{j}^{1} \\
v_{i j k}^{2}
\end{array}\right] \sim N\left(\left[\begin{array}{l}
0 \\
0
\end{array}\right],\left[\begin{array}{cc}
1 & \rho \\
\rho & \sigma^{2}
\end{array}\right]\right)}
\end{gathered}
$$

where the variables are defined as in (3). The first equation describes MP $i$ 's decision to dissent, $D_{i}$, in the 39th Parliament. This is a function of re-election incentives, margin of victory, party fixed effects, controls and an MP-specific idiosyncratic error term, $v_{i}^{1}$. The second equation is identical to (3) and contains the coefficients of interest: $\beta_{2}$ and $\beta_{3}$. Finally, $v_{i}^{1}$ and $v_{i j k}^{2}$ are the MP- and 
vote-specific error terms whose correlation is described by $\rho$. The ex ante expectation is that $\rho$ will be less than zero - after controlling for MP- and vote-specific factors, remaining variation is likely driven by vote-varying subject matter elements which likely mitigate MP dissent between bills readings. ${ }^{26}$

Formally, this bivariate sample selection model is identified via the non-linearity of its specification. Identification via non-linearity is notoriously unreliable without an exclusion restriction however. As few obvious instruments are available in the case of MP dissent, I follow Rosenbaum (2002) and Altonji, Elder and Taber (2005) and treat $\rho$ as unidentified parameter and fix it a pre-selected levels. Sensitivity analysis is performed by varying $\rho$ from -0.2 to 0 to 0.2 .

Table 6 displays results for four models. (1) presents coefficients for a specification where $\rho$ is estimated. Correlation between error terms equals -0.05 (not shown), indicating the expected negative selection. All coefficients of interest are now statistically significant at a 5 percent level. Importantly, the coefficient on the interaction is negative and the joint hypothesis is statistically significantly different from zero (the F-stat equals 5.74). For a one standard deviation decrease in expected margin of victory, reputation building predicts a 2.3 percent increase in the probability that an MP will dissent on any given vote. Restrictions on $\rho$ generate very similar coefficient estimates and the null of no reputation building is rejected in three our four formulations. Only when positive selection is imposed is the joint hypothesis insignificant. Due to this consistency of parameter values, as the error-term correlation is estimated, rather than imposed, and as the coefficient estimates remain robust across the sensitivity analysis presented in models (2) through (4), (1) from Table 6 are my preferred vote-level results. Local elections matter more than conventionally believed for Canadian federal elections and, once selection on unobservables is incorporated, reputation building appears to explain much of the puzzle of MP dissent.

\footnotetext{
${ }^{26}$ For example, committees may revise particular provisions of a bill between second and third readings.
} 


\section{Discussion and Conclusion}

Parliaments are dominated by political parties and it is a stylized fact that parties and party leadership control agendas and vital government parameters. Yet, this research demonstrates that local politics and MP reputation matter more than previously believed. By exploiting a unique situation where MPs cast dissenting votes, I theoretically and empirically disentangle the influence of MPs' conflicting incentives and demonstrate that dissent has a politically meaningful function in local ridings. MP dissent presented a puzzle for the standard interpretation of party politics representatives who cast votes against their party's proscribed position rarely influenced legislative outcomes but still incurred some cost for their action. The paper presented a model of optimal voting strategy whereby MPs attempt to build reputations with their local constituents. An empirical hypothesis was formulated and tested based on MPs' equilibrium voting rules. Evidence suggests that MP do attempt to build reputations. For a matched sample of politicians, holding a seat in a competitive riding increases the probability of dissent by between 13 and 19 percent. On a vote-byvote basis, after controlling for legislation-specific fixed effects and unobserved heterogeneity, MPs whose previous margin of victory was one standard deviation below the mean are 2.3 percent more likely to dissent on any given vote. Taken together, this is a compelling reason to believe that MPs attempt to send signals to their constituents via their behavior in legislature.

Within the Canadian political context, these results run contra to the conventional wisdom that views parties as especially forceful. Yet, the findings complement recent work by Kendall and Rekkas (2012). Kendall and Rekkas show that incumbent Canadian MPs experience a notable individual incumbency effect, while parties' contribution to re-election prospects is small or even negative. A reconsideration of the prevailing Canadian perspective may be warranted as individual MPs appear to have more autonomy than believed. More generally, these results contribute to a re-interpretation of the role of parties as conduits of information (Carey, 2007) and of party leadership's ability to aggressively push policy agendas (Kam et al., 2010).

Reputation is the bridge between action and expectations (Mailath and Samuelson, 2013). Politicians who operate in parliaments need to manage the expectations and demands of parties, constituents and other interests. Understanding the magnitude and relative influence of these 
pressures helps to elucidate the range of the incentives that politicians face. It is also likely that the action-expectation link extends to other political actors such as lobbyists, special interests and corporations and reputation helps to interpret behavior that may otherwise appear irrational. A logical next step in the analysis of reputation is to develop and test equilibrium strategies for these actors to determine how pervasive reputation building is across the political spectrum. 


\section{References}

Aghion, Philippe, Alberto Alesina, and Francesco Trebbi. 2004. "Endogenous political institutions." The Quarterly Journal of Economics, 119(2): 565-611.

Altonji, Joseph G, Todd E Elder, and Christopher R Taber. 2005. "Selection on observed and unobserved variables: Assessing the effectiveness of Catholic schools." Journal of political economy, 113(1): 151-184.

Angrist, Joshua D, and Jörn-Steffen Pischke. 2008. Mostly harmless econometrics: An empiricist's companion. Princeton University Press.

Ansolabehere, Stephen, John M de Figueiredo, and James M Snyder Jr. 2003. "Why is There so Little Money in US Politics?" The Journal of Economic Perspectives, 17(1): 105-130.

Besley, T. 2007. Principled Agents?: The Political Economy of Good Government. The Lindahl Lectures, OUP Oxford.

Besley, Timothy, and Anne Case. 2003. "Political institutions and policy choices: evidence from the United States." Journal of Economic Literature, 41(1): 7-73.

Besley, Timothy, and Stephen Coate. 2001. "Lobbying and welfare in a representative democracy." The Review of Economic Studies, 68(1): 67-82.

Besley, Timothy, and Stephen Coate. 2003. "Centralized versus decentralized provision of local public goods: a political economy approach." Journal of public economics, 87(12): 2611-2637.

Bowler, Shaun, David M Farrell, Richard S Katz, et al. 1999. Party discipline and parliamentary government. Ohio State University Press Columbus.

Bronars, Stephen G, and John R Lott Jr. 1997. "Do Campaign Donations Alter How a Politician Votes-Or, Do Donors Support Candidates Who Value the Same Things That They Do." JL \& Econ., 40: 317.

Carey, John M. 2007. "Competing principals, political institutions, and party unity in legislative voting." American Journal of Political Science, 51(1): 92-107.

Cox, Gary W. 2000. "On the effects of legislative rules." Legislative Studies Quarterly, 169-192.

Diermeier, Daniel, and Timothy J Feddersen. 1998. "Cohesion in legislatures and the vote of confidence procedure." American Political Science Review, 611-621.

Dixit, Avinash, Gene M Grossman, and Elhanan Helpman. 1997. "Common agency and coordination: General theory and application to government policy making." Journal of Political Economy, 105(4): 752-769.

Faas, Thorsten. 2003. "To defect or not to defect? National, institutional and party group pressures on MEPs and their consequences for party group cohesion in the European Parliament." European Journal of Political Research, 42(6): 841-866. 
Frölich, Markus. 2004. "Finite-sample properties of propensity-score matching and weighting estimators." Review of Economics and Statistics, 86(1): 77-90.

Garner, Christopher, and Natalia Letki. 2005. "Party structure and backbench dissent in the Canadian and British Parliaments." Canadian journal of political science, 38(02): 463-482.

Glynn, Adam N, and Kevin M Quinn. 2010. "An introduction to the augmented inverse propensity weighted estimator." Political Analysis, 18(1): 36-56.

Hainmueller, Jens, and Holger Lutz Kern. 2008. "Incumbency as a source of spillover effects in mixed electoral systems: Evidence from a regression-discontinuity design." Electoral Studies, $27(2): 213-227$.

Harris, Mark N, Paul Levine, and Christopher Spencer. 2011. "A decade of dissent: explaining the dissent voting behavior of Bank of England MPC members." Public Choice, 146(3): 413442.

Hix, Simon. 2002. "Parliamentary behavior with two principals: preferences, parties, and voting in the European Parliament." American Journal of Political Science, 688-698.

Ho, Daniel E, Kosuke Imai, Gary King, and Elizabeth A Stuart. 2007. "Matching as nonparametric preprocessing for reducing model dependence in parametric causal inference." Political analysis, 15(3): 199-236.

Kam, Christopher. 2001. "Do ideological preferences explain parliamentary behaviour? Evidence from Great Britain and Canada." Journal of Legislative Studies, 7(4): 89-126.

Kam, Christopher J. 2009. Party Discipline and Parliamentary Politics. Cambridge University Press.

Kam, Christopher, William T Bianco, Itai Sened, and Regina Smyth. 2010. "Ministerial selection and intraparty organization in the contemporary british parliament." American Political Science Review, 104(2): 289-306.

Kendall, Chad, and Marie Rekkas. 2012. "Incumbency advantages in the Canadian Parliament." Canadian Journal of Economics/Revue canadienne d'économique, 45(4): 1560-1585.

Krehbiel, Keith. 1993. "Where's the Party?" British Journal of Political Science, 23(2): 235-266.

Krehbiel, Keith. 1999. "Paradoxes of parties in congress." Legislative Studies Quarterly, 31-64.

Krehbiel, Keith. 2000. "Party discipline and measures of partisanship." American Journal of Political Science, 212-227.

Landier, Augustin, David Sraer, and David Thesmar. 2009. "Optimal dissent in organizations." The Review of Economic Studies, 76(2): 761-794.

List, John A, and Daniel M Sturm. 2006. "How elections matter: Theory and evidence from environmental policy." The Quarterly Journal of Economics, 121(4): 1249-1281. 
Longley, Neil. 1998. "Legislative systems with absolute party discipline: Implications for the agency theory approach to the constituent-legislator link." Public Choice, 97(1-2): 121-141.

Mailath, George J, and Larry Samuelson. 2013. "Reputations in Repeated Games." Penn Institute for Economic Research, Department of Economics, University of Pennsylvania.

Meade, Ellen E, and David Stasavage. 2008. "Publicity of Debate and the Incentive to Dissent: Evidence from the US Federal Reserve*." The Economic Journal, 118(528): 695-717.

Milligan, Kevin, and Marie Rekkas. 2008. "Campaign spending limits, incumbent spending, and election outcomes." Canadian Journal of Economics/Revue canadienne d'économique, 41(4): 1351-1374.

Palmer, Matthew SR. 1995. "Toward an economics of comparative political organization: Examining ministerial responsibility." Journal of Law, Economics and Organization, 11(1): 167-191.

Potters, Jan, and Randolph Sloof. 1996. "Interest groups: A survey of empirical models that try to assess their influence." European Journal of Political Economy, 12(3): 403-442.

Rosenbaum, Paul R. 2002. Observational studies. Springer.

Rosenbaum, Paul R, and Donald B Rubin. 1984. "Reducing bias in observational studies using subclassification on the propensity score." Journal of the American Statistical Association, 79(387): 516-524.

Smith, Jeffrey A., and Petra E. Todd. 2005. "Does matching overcome LaLonde's critique of nonexperimental estimators?" Journal of Econometrics, 125(1-2): 305 - 353.

Stratmann, Thomas. 2005. "Some talk: Money in politics. A (partial) review of the literature." In Policy Challenges and Political Responses. 135-156. Springer.

Voigt, Stefan. 2011. "Positive constitutional economics II - a survey of recent developments." Public Choice, 146(1): 205-256.

Wright, Gerald C, and Brian F Schaffner. 2002. "The influence of party: Evidence from the state legislatures." American Political Science Review, 96(2): 367-379. 
Table 1: Descriptive Statistics on Dissent in the 39th Parliament of Canada

\begin{tabular}{lcc}
\hline & Total & Dissenting \\
\hline Members of Parliament (MPs) & 308 & 188 \\
Number of MPs per party: & 124 & 64 \\
Conservative Party & 103 & 89 \\
Liberal Party & 29 & 21 \\
New Democrat Party & 51 & 14 \\
Bloc Québécois & 1 & \\
Independent & 297 & 175 \\
Seeking re-election & 20 & 13 \\
Not seeking re-election & 65 & 30 \\
Number of bills & Mean & Std Dev \\
\hline & & \\
& 21.9 & 15.4 \\
Margin of victory in Preceding Election (\%): & 20.0 & 15.3 \\
All MPs & & \\
MPs who Dissented at Least Once & 1.09 & 10.36 \\
Rate of Dissent on any Parliamentary Vote (\%): & 1.77 & 13.18 \\
All MPs & & \\
MPs who Dissented at Least Once & 3.24 & 17.89 \\
Rate of Dissent on Bills with any Dissenting Vote (\%): & 5.40 & 22.60 \\
$\quad$ All MPs & & \\
MPs who Dissented at Least Once & &
\end{tabular}

Party membership reflects counts at the beginning of the session. 
Table 2: Increase in MPs' Probability of Casting a Dissenting Vote Conditional on Winning a Competitive Election

\begin{tabular}{lc}
\hline & $\begin{array}{c}\text { Average treatment } \\
\text { effect on the treated }\end{array}$ \\
\hline Less than 10\% margin of victory & $0.127^{* *}$ \\
& $(0.059)$ \\
Number of observations & 313 \\
Less than 5\% margin of victory & $0.186^{* * *}$ \\
Number of observations & $(0.070)$ \\
\hline
\end{tabular}

$* * *$ - p-value $<0.01 ; * *$ - p-value $<0.05{ }^{*}$ - p-value $<0.10$.

Bootstrapped standard errors in parentheses.

The values in the table reflect the difference in the probability that an MP whose previous electoral victory was competitive will cast a dissenting vote minus the probability that an MP whose previous election was not competitive will cast a dissenting vote. Results are generated from a matched sample where matching was completed using a Gaussian kernel. The sample was trimmed by 2 percent on each end of the distribution and the number of observations reflects MPs who were on the common support. Matches were assigned according to variables that were determined prior to voting decisions. 
Table 3: Effect of Re-election and Margin of Victory on the Number of Times MPs Cast Dissenting Votes

\begin{tabular}{|c|c|c|c|}
\hline & Coefficient & $\begin{array}{l}\text { Marginal Effect } \\
\text { at } 10 \% \text { Margin } \\
\text { of Victory }\end{array}$ & $\begin{array}{l}\text { Marginal Effect } \\
\text { at } 5 \% \text { Margin of } \\
\text { Victory }\end{array}$ \\
\hline Electoral Margin & $\begin{array}{c}0.008 \\
(0.009)\end{array}$ & 0.009 & 0.009 \\
\hline Re-election & $\begin{array}{l}0.575^{*} \\
(0.328)\end{array}$ & 0.492 & 0.517 \\
\hline Margin*Re-election & $\begin{array}{c}-0.018^{*} \\
(0.010)\end{array}$ & -0.019 & -0.020 \\
\hline Controls & Yes & & \\
\hline Number of observations & 310 & & \\
\hline Chi-square - Reputation Hypothesis & $3.13^{*}$ & & \\
\hline \multicolumn{4}{|c|}{$\begin{array}{l}* * * \text { - p-value }<0.01 ;{ }^{* *}-\mathrm{p} \text {-value }<0.05 ;^{*}-\mathrm{p} \text {-value }<0.10 \text {. } \\
\text { Robust standard errors in parentheses. Control variables include: party membership and whether } \\
\text { the MP is a member of the cabinet. }\end{array}$} \\
\hline \multicolumn{4}{|c|}{$\begin{array}{l}\text { This table presents the coefficient estimates and marginal effects of a negative binomial } \\
\text { count model where the dependent variable is the number of dissenting votes cast by an MP. } \\
\text { Marginal effects are calculated at both the } 10 \text { and } 5 \text { percent level. The Chi-squared statistic tests } \\
\text { the restriction that sum of the re-election coefficient and (negative of) the margin-re-election } \\
\text { interaction term are different from zero. }\end{array}$} \\
\hline
\end{tabular}


Table 4: Marginal Effect of Reputation Building on Dissent using Vote-level Data

\begin{tabular}{|c|c|c|}
\hline & (1) & $(2)$ \\
\hline Electoral Margin & $\begin{array}{c}0.02 \\
(0.02)\end{array}$ & $\begin{array}{c}0.03 \\
(0.04)\end{array}$ \\
\hline Re-election & $\begin{array}{c}0.63 \\
(0.68)\end{array}$ & $\begin{array}{c}1.01 \\
(1.21)\end{array}$ \\
\hline Margin*Re-election & $\begin{array}{l}-0.02 \\
(0.02)\end{array}$ & $\begin{array}{l}-0.05 \\
(0.04)\end{array}$ \\
\hline Controls & Yes & Yes \\
\hline Legislation Fixed Effects & Yes & Yes \\
\hline Party Fixed Effects & Yes & Yes \\
\hline Method & $\begin{array}{c}\text { Least } \\
\text { Squares }\end{array}$ & Probit \\
\hline Number of observations & 32216 & 32216 \\
\hline F-stat - Reputation Hypothesis & 0.87 & 0.73 \\
\hline \multicolumn{3}{|c|}{$\begin{array}{l}* * * \text { p-value }<0.01 ; * * \text { - p-value }<0.05 ;{ }^{*} \text { - p-value }<0.10 . \\
\text { Clustered standard errors in parentheses for }(1) ; \text { clustered on in- } \\
\text { dividual MPs. Standard errors calculated using delta method for } \\
\text { the marginal effects in }(2) \text {. Control variables include: provincial } \\
\text { dummies and whether the MP is a member of the cabinet. All } \\
\text { marginal effects scaled to reflect probabilities. }\end{array}$} \\
\hline \multicolumn{3}{|c|}{$\begin{array}{l}\text { This table presents the marginal effect of linear probability } \\
\text { and probit models on the likelihood that an MP will cast a } \\
\text { dissenting vote on any given vote. The F-stat (Chi-squared for } \\
\text { the probit model) tests the restriction that sum of the re-election } \\
\text { coefficient and (negative of) the margin-re-election interaction } \\
\text { term are different from zero. }\end{array}$} \\
\hline
\end{tabular}


Table 5: Robustness Checks on Basic Vote-level Models of Reputation Building

\begin{tabular}{lccc}
\hline & $(1)$ & $(2)$ & $(3)$ \\
\hline Electoral Margin & 0.04 & 0.03 & \\
Re-election & $(0.06)$ & $(0.02)$ & \\
Margin*Re-election & 1.60 & 0.73 & -0.01 \\
& $(1.57)$ & $(0.63)$ & $(0.01)$ \\
Controls & -0.06 & -0.03 & Yes \\
Legislation Fixed Effects & $(0.06)$ & $(0.02)$ & Yes \\
Party Fixed Effects & Yes & Yes & Yes \\
& Yes & Yes & Two-staged \\
Method & Yes & & Least Squares \\
Restriction & & Propensity & MPs Running \\
& Least Squares & Weighting & for Re-election \\
Number of observations & Bills with & None & 30391 \\
F-stat - Reputation Hypothesis & Dissent & & 1.62 \\
\hline
\end{tabular}

*** - p-value $<0.01{ }^{* *}$ - p-value $<0.05 ;^{*}$ - p-value $<0.10$.

Clustered standard errors in parentheses; clustered on individual MPs. Control variables include: provincial dummies and whether the MP is a member of the cabinet. All marginal effects scaled to reflect probabilities.

This table presents three robustness checks on the results from Table 4. (1) restricts the sample to only bills where at least one dissenting vote was cast. (2) uses inverse propensity weighting. (3) employs an instrumental variable strategy which relaxes the assumptions regarding the variable used for the expected margin of victory. The F-stat tests the sum of the re-election coefficient and (negative of) the margin-re-election interaction term for (1) and (2) and tests whether the single coefficient in (3) are different from zero. 
Table 6: Marginal Effect of Reputation Building using Vote-level Data and Accommodating Selection on Unobservables

\begin{tabular}{lcccc}
\hline & $(1)$ & $(2)$ & $(3)$ & $(4)$ \\
\hline Electoral Margin & $0.06^{* * *}$ & $0.05^{* *}$ & 0.01 & $0.09^{* * *}$ \\
Re-election & $(0.02)$ & $(0.02)$ & $(0.05)$ & $(0.03)$ \\
& $1.53^{* *}$ & $1.36^{* *}$ & 0.71 & $2.01^{* *}$ \\
Margin*Re-election & $(0.65)$ & $(0.67)$ & $(1.18)$ & $(0.86)$ \\
& $-0.05^{* * *}$ & $-0.04^{* *}$ & -0.02 & $-0.06^{* *}$ \\
Controls & $(0.02)$ & $(0.02)$ & $(0.05)$ & $(0.03)$ \\
Legislation Fixed Effects & Yes & Yes & Yes & Yes \\
Party Fixed Effects & Yes & Yes & Yes & Yes \\
Restriction & Yes & Yes & Yes & Yes \\
Number of observations & Unconstrained & $\rho=0$ & $\rho=0.2$ & $\rho=-0.2$ \\
F-stat - Reputation Building & $5.74^{* *}$ & $4.17^{* *}$ & 0.35 & 32216 \\
\hline
\end{tabular}

*** - p-value $<0.01 ;{ }^{* *}$ - p-value $<0.05{ }^{*}$ - p-value $<0.10$.

Clustered standard errors in parentheses; clustered on individual MPs. Control variables include: provincial dummies and whether the MP is a member of the cabinet. All marginal effects scaled to reflect probabilities

This table presents four models that employ a Heckman-style selection equation. (1) permits $\rho$ to be estimated freely (equals -0.05). (2) through (4) treat $\rho$ as unidentified and set it to pre-specified levels (as indicated in the table). The F-stat tests the restriction that sum of the re-election coefficient and (negative of) the margin-re-election interaction term is different from zero. 